\title{
Economically Useful Plants of Sri Lanka Part IV* Screening of Sri Lanka Plants for Tannins
}

\author{
S. J. BALASOORIYA, S. SOTHEE WARAN \\ Department of Chemistry, University of Peradeniya, Peradeniya, Sri Lanka. \\ AND
}

S. Balasubramanium

Department of Botany, University of Peradeniya, Peradeniya, Sri Lanka.

(Date of receipt : 27 April 1982)

(Date of acceptance : 26 October 1982)

\begin{abstract}
Several Sri Lankan plants have boen assayed for their tannin content. Percentas e total tannins as determined by the hide powder method have been compared with the results obtained by the polyclar adsorption method. Infra-red spectroscopy has been used to classify the tannins isolated as either belonging to the condensed type or hydrolysable type. The barks of Carapa granata and Ceriops tagal have been identified as two new tannin rich sources.
\end{abstract}

\section{Introduction}

Tannins are polyphenolic substances widely distributed among higher plants. They are important economically as agents for the tanning of leather and they impart flavour to wines. Recently ${ }^{4}$ evidence has been obtained in support of their potential value as cytotoxic or anti-neoplastic agents. In addition, tannins are now being increasingly used ${ }^{2}$ in the manufacture of plastics, paints, ceramics and water softening agents. The demand for tannin is very great and hence a survey of new sources of plant materials for tannins has assumed increasing importance. Within the overall programme ${ }^{5}$ of the Chemical Investigation of Economically useful Plants of Sri Lanka, a survey of Sıi Lanka plants for their tannin content was also undertaken. Two types of tannins are known. They are hydrolysable tannins and non-hydrolysable tannins. The leather tanning industry requires mainly watersoluble tannins.

\section{Results and Discussion}

In the present investigation, the ability of tannins to precipitate gelatin from solution ${ }^{3}$ has been used to test qualitatively the presence of tannins in plant extracts. The extracts which have a positive gelatin-salt reagent and neutral feric chloride tests were adjudged to contain tannins in detectable amounts. The plant extracts which gave positive qualitative tests were analysed quantitatively. The methanol

* For Part III see A.A.L. Gunatilaka and S. Sotheeswaran, J. Natn. Sci. Coun. Sri Lanka, $1980,8(1), \quad 11-39$ 
defatted extracts which had a yield of greater than twenty percent (dry plant weight basis) were subiected to adsorption with hide powder ${ }^{2}$ and the percentages of the material adsorbed weie regarded as indicating the amount of tannins in the respective plant extracts which could be used in the tanning industry. The results have been compared with the yields of tannins obtained using adsorption on the polyamide ${ }^{3}$ polyclar. The Table 1 gives the list of 43 samples subjected to screening for tannins. The water solubility of the defatted methanol extracts is also given in the Table 1. Since hydrolysable tannins aie esters and non-hydiolysable (condensed) tannins are polymers of phenolic compounds, infrared spectroscopy colild be used to differentiate between the two major classes of tannins. Tannins isolated in the present study have been classified using this method and the results are included in the Table.

The nuts of Terminalia chebula used in this country as a vegetable tanning material in the production of tanned leather gave for one sample, a defatted methanol extract yield of $44.7 \%$. In this case, the total tannin yield as determined by the hide powder and by the polyamide adsorption methods were $27.3 \%$ and $27.1 \%$ respectively. However, contrary to published results ${ }^{3}$ the tannin yields obtained by the two methods were not in agreement in many instances. Cassia aurriculata bark extracts are widely used in India as a vegetable tanning material. ${ }^{1}$ The present study has shown that the tannins of Cassiu auriculata are of the condensed type. The defatted methanol extracts of the bark of Ceriops tagal contain water-soluble tannins which are of hydrolysable typz. More than fifty parcent of these defatted extracts are capable of tanning leather. In many instances the yield of tannin from the Sri Lankan mangrove species was low. Carapa granata (Meliaceae) bark extract was found to be a good source of tannin. Even though this tannin belongs to the condensed type, its solubility in water and adsorbability on chromed hide and polyamide would make it a suitable tanning material. This is the first report on the tannin yields of several plant patts including the barks of Ceriops tagal and Curapa granats.

\section{Experimental}

The plant materials were collected from various localities in Sri Lanka, mainly in mangrove swamps. Infrared spectra of defatted methanol extracts with a yield of $>20 \%$ were obtained using a Perkin Elmer 257 spectrophotometer. Hide powder was prepared from cattle skin purchased locally. The polyamide, polyclar, was putchased.

\subsection{Qualitative test for Tannins}

The powdered plant part $(10 \mathrm{~g})$ was extracted with methanol for about $2 \mathrm{hr}$. The extract was solvent evaporated and the dried residue was defatted by refluxing with light petroleum for about $4 \mathrm{hr}$. The residue was dried again. Hot distilled water $(25 \mathrm{ml})$ was added to the residue and the mixture was stirred well. $10 \% \mathrm{NaCl}(3-4$ drops) was added and the solution was filtered into 4 test tubes. To each tube the following reagents were added. 


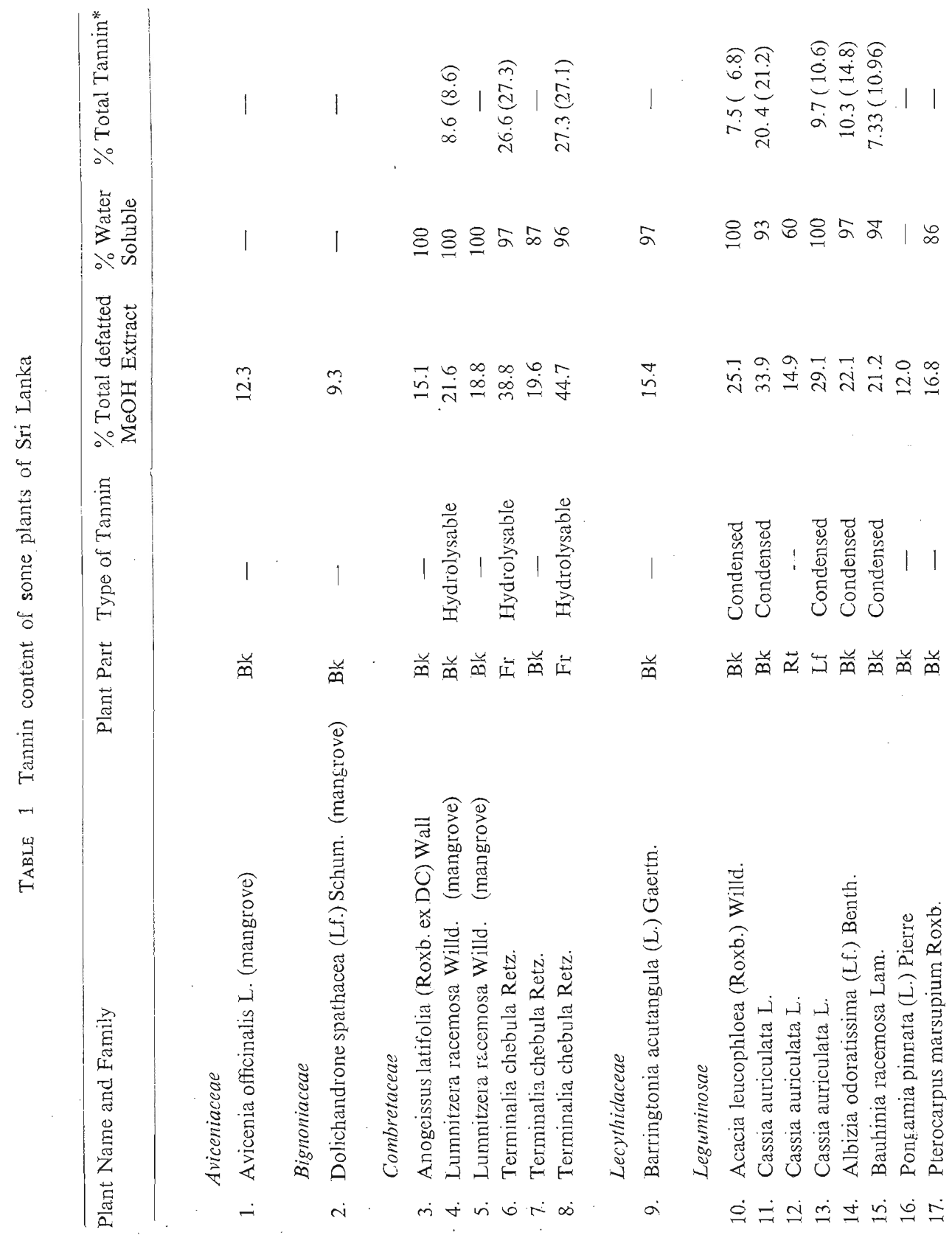



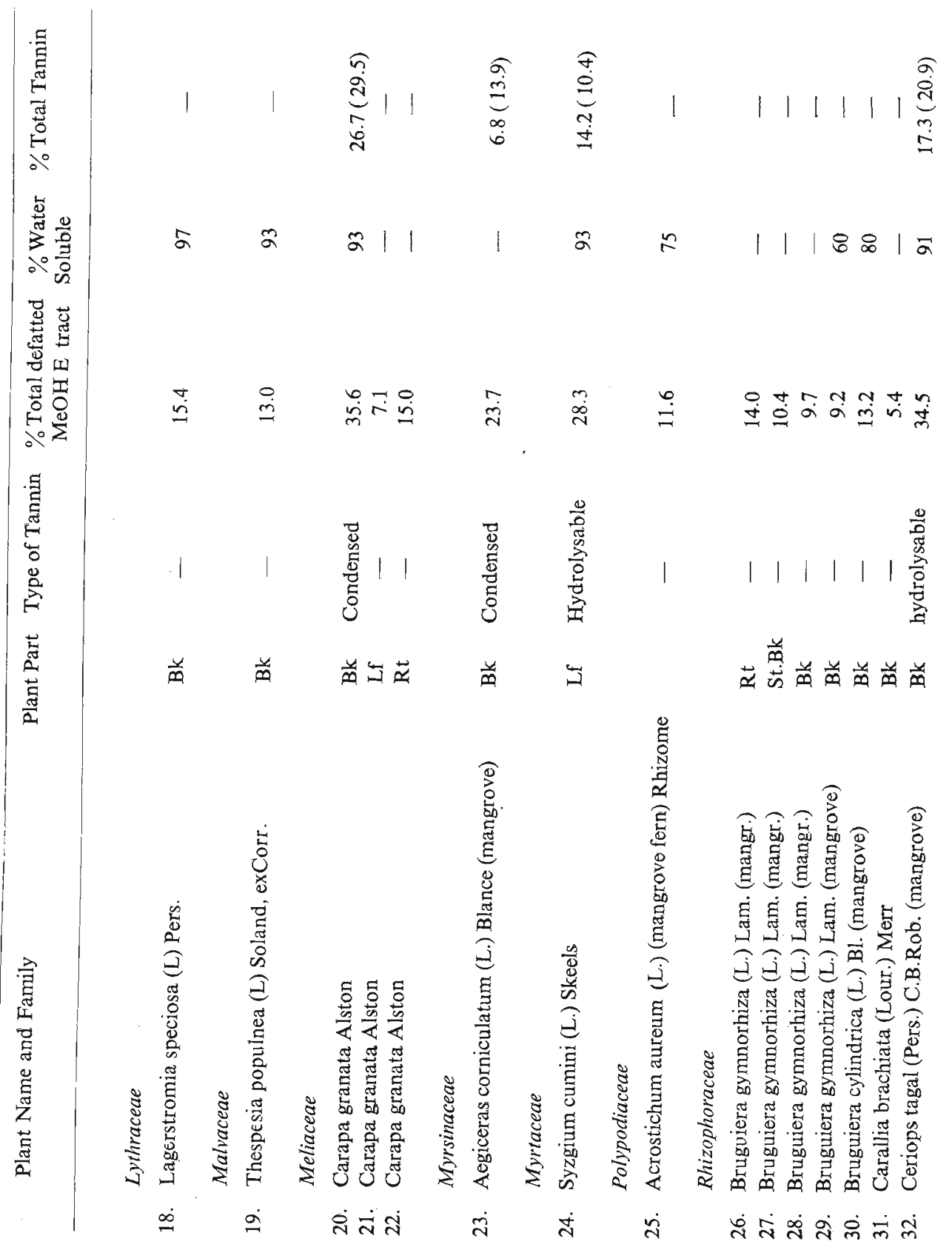


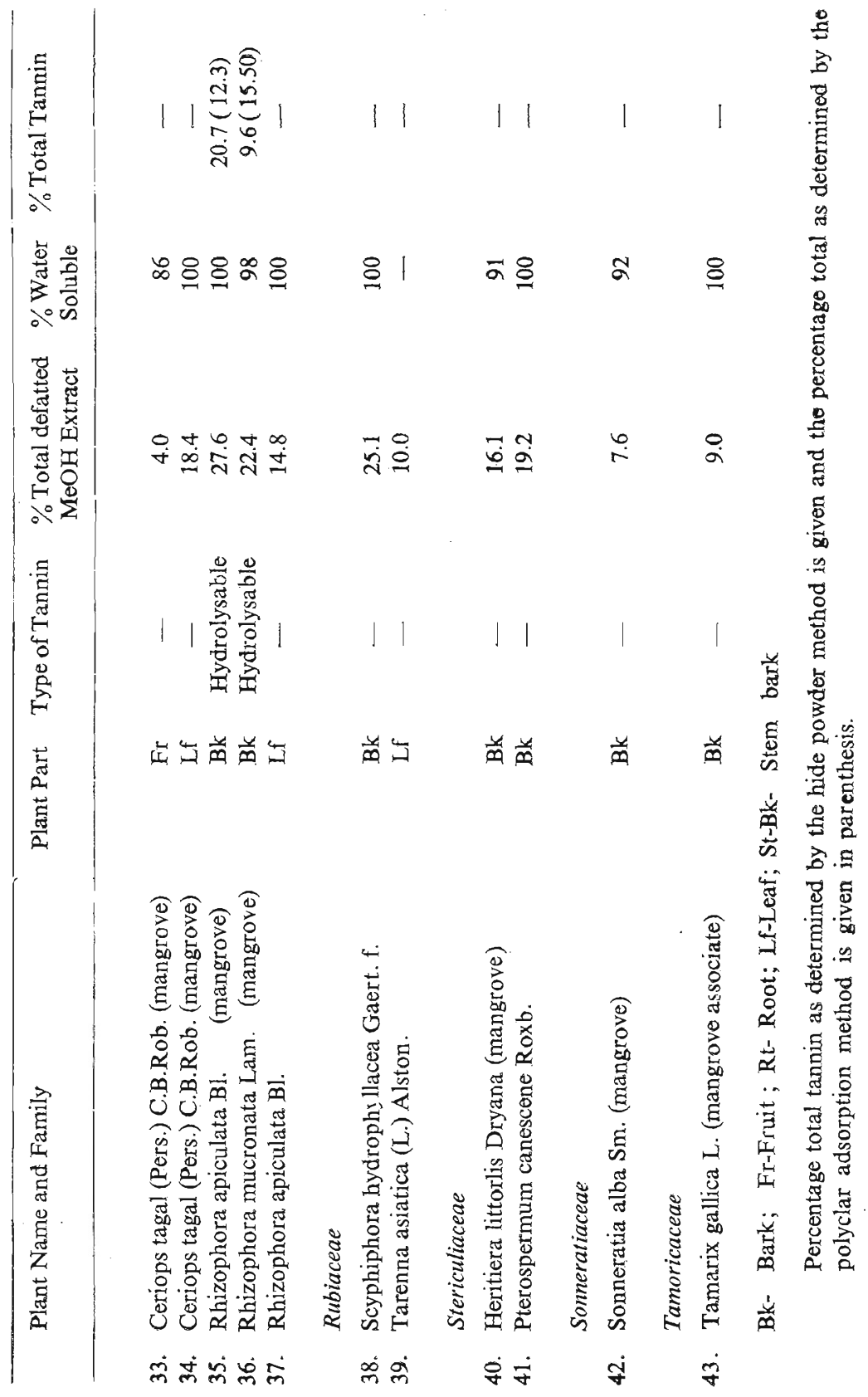


1. 4-5 Drops of $1 \%$ gelatin: 2. 4-5 Diops of gelatin-salt reagent ( $1 \%$ gelatin + $10 \% \mathrm{NaCl}) ; 3$. Neutral ferric chloride; 4 . Used as a reference. If a precipitate was obtained in tubes 1 and 2 and if tube 3 also gave a positive test, then tannins were considered to be present in detectable amounts in the test extract.

\subsection{Quantitative assay}

The powdered plant part $(10 \mathrm{~g})$ was extracted with methanol and the extract was defatted as before. The defatted methanol extract yield was recorded.

\subsubsection{Preparation of chromed hide powder}

De-haired cattle skin was dried well and was giound. The powder was sieved and the fine dry powder was used. Dry hide powder $(3.12 \mathrm{~g})$ was digested with ten times its weight of distilled water for $1 \mathrm{hr}$. A chlome alum solution $(3 \% \mathrm{w} / \mathrm{v})$ was added and the contents were frequently stirred for several hours. After standing overnight the material was transferred to a cloth and was squeezed. The material was washed thoroughly with water to remove excess alum.

\subsubsection{Adsorption on chromed hide}

The defatted extract $(0.185 \mathrm{~g})$ was dissolved in distilled water $(200 \mathrm{ml})$ and was filtered free of any insoluble matter. $25 \mathrm{ml}$ of this solution was evaporated to dryness and the weight of the residue was noted. Another $50 \mathrm{ml}$ of this solution was added to the prepased chromed hide powder and was agitated for about 10 min. The contents were filtered through a cloth. Kaolin was thoroughly mixed with the filtrate and the mixture was filtered. $25 \mathrm{ml}$ of this filtrate was evaporated to dryness. From the weight of the residue, the amount of substance adsorbed onto the chromed hide was calculated. The tannin contents have been expressed as percentages and are given in the Table 1.

\subsubsection{Adsorption on polyclar}

The defatted extract $(1.5 \mathrm{~g})$ was dissolved in $50 \mathrm{ml}$ water. $25 \mathrm{ml}$ of this solution. was treated with polyclar $(3 \mathrm{~g})$. The mixture was stirred for $4 \mathrm{hr}$ and was filtered. Kaolin $(2 \mathrm{~g})$ was added to the filtrate and the mixture was stirred. The mixture was filtered and was evaporated to dryness. $25 \mathrm{ml}$ of the remaining aqueous solution of the defatted extract was also evaporated to dryness. From the weight of the residues, the amount of tannin adsorbed onto the polyamide was obtained and the tannin contents have been expressed as percentages in Table 1.

\subsection{Solubility determination}

$50 \mathrm{mg}$ of the tannin was treated with cold water $(1 \mathrm{ml})$. The insoluble matter was filtered and the percentage solubility was calculated. 


\section{Acknowledgement}

The authors thank the Natural Resources, Energy and Science Authority of Sri Lanka and the Royal Society of Chemistry, London for research grants. Professor Leslie Gunatilaka is thanked for stimulating discussions. Technical assistance rendered by Mr. Z. A. M. Faisal is also acknowledged.

\section{References}

1. Aswath, K., RaO, N. \& Janniah, S. L., (1934) J. Ind. Inst. Sci., 17A, 95.

2. Atal, C. K., Srisatva, J. B., Wali, B. K., Chakravorty, R. B., Dhawan, B. N. \& Rastogi, R. P., (1978). Ind. J. of Exptl. Biol., 16: 330.

3. Deshapande, V. H. \& Kumari, L. Chem. Abstract., (1977), 108016.

4. Fong, H. S., TIN-WA, M., \& Farnsworth, N. R., (1977). in "Phytochemical Screening", Material prepared for College of Pharmacy, Univ. of Illinois, Chicago (USA), p. 6.

5. Gunatilaka, A. A. L. \& Sotheeswaran, S., (1980). J. Natn. Sci. Coun. Sri Lanka, 8 (1):11-39. 